\title{
LA CORTE PENAL INTERNACIONAL HACE HISTORIA: PRIMER VEREDICTO DE CULPABILIDAD Y PRIMERA SENTENCIA SOBRE REPARACIÓN A LAS VÍCTIMAS EN EL CASO DE EL FISCAL V. THOMAS LUBANGA DYILO
}

\author{
Ana Gemma López MarTín * \\ Profesora Titular de Derecho Internacional Público \\ Facultad de Derecho de la UCM \\ anagema@der.ucm.es
}

\section{INTRODUCCIÓN}

El año 2002 fue un año histórico para el Derecho internacional y, más concretamente, para la consolidación de la responsabilidad penal internacional del individuo, pues ese año entró en vigor el Estatuto de Roma de 17 de julio de 1998 y, en consecuencia, comenzó su singladura la Corte Penal Internacional (CPI). Tan importante hecho tuvo lugar exactamente el 1 de julio de 2002, una vez que el 11 de abril de 2002 se consiguió el depósito del sexagésimo instrumento de ratificación; número exigido por el art. 126 del Estatuto de la CPI para entrar en vigor ${ }^{1}$. Actualmente el número de Estados parte de la CPI asciende a 121.

* Trabajo realizado en el marco del Proyecto I+D+I (Ministerio de Ciencia e Innovación), referencia DER2010-15605, subprograma JURI.

${ }^{1}$ Diez países depositaron su instrumento de ratificación simultáneamente en la ceremonia especial que celebró la ONU el 11 de abril de 2002, alcanzando así las sesenta ratificaciones necesarias para lograr que el Estatuto de Roma entrara en vigor: Bosnia-Herzegovina, Bulgaria, Camboya, Eslovaquia, Irlanda, Jordania, Mongolia, Níger, República Democrática del Congo y Rumania. La entrada en vigor se produjo el primer día del mes siguiente después de pasados sesenta días (1 de julio de 2002), según lo dispuesto por el art. 126 del Estatuto: «Entrada en vigor.-1. El presente Estatuto entrará en vigor el primer día del mes siguiente al sexagésimo día a partir de la fecha en que se deposite en poder del Secretario General de las Naciones Unidas el sexagésimo instrumento de ratificación, aceptación, aprobación o adhesión».

En el momento de su entrada en vigor ascendía a 76 el número de ratificaciones del Estatuto de la CPI. España lo ratificó el 24 de octubre de 2000 (vid. BOE, núm. 126, de 27 de mayo de 2002). El estado actual de las ratificaciones, en orden cronológico, puede consultarse en el siguiente enlace: www.icc-cpi.int/Menus/ASP/states+parties/States+Parties+_+ Chronological+list.htm. 
Si 2002 pasará a los anales de la historia del Derecho penal internacional, también lo hará el año 2012, pues, casi una década después de empezar a funcionar, la Corte Penal Internacional ha dictado su primera sentencia condenatoria. Concretamente, el 14 de marzo de 2012 la Sala de Primera Instancia de la $\mathrm{CPI}^{2}$ consideró a Thomas Lubanga Dyilo culpable del crimen de guerra de «reclutamiento o alistamiento de niños menores de quince años en las fuerzas armadas o grupos, y utilizarlos para participar activamente en hostilidades», el cual aparece tipificado en el art. 8.2.e). vii) del Estatuto de la CPI. El veredicto, adoptado por unanimidad de los tres jueces - el presidente Adrian Fulford (Reino Unido), Elizabeth Odio Benito (Costa Rica) y René Blattman (Bolivia)—, concluye que el acusado «sabía» y «era consciente» del crimen de reclutamiento de menores que estaba cometiendo, por lo que, según lo dispuesto en el art. 25.3 del Estatuto CPI, «es penalmente responsable y puede ser penado» ${ }^{3}$.

En consonancia con este veredicto, el 10 de julio de 2012 Thomas Lubanga fue condenado a una pena de catorce años de prisión ${ }^{4}$. Habida cuenta que lleva ya seis años bajo custodia de la Corte en la prisión de Haaglanden en Scheveningen (La Haya), sólo le quedan por cumplir ocho años de condena. Una cuestión aún pendiente es la relativa al lugar donde cumplirá el resto de su condena. Austria, Dinamarca, Finlandia, Reino Unido y Serbia han declarado su voluntad de recibir al acusado.

Ciertamente sorprende lo reducido de la condena: catorce años por la comisión de graves crímenes de guerra como son los del reclutamiento y utilización de niños soldados. A este respecto indicar que la Fiscalía, dirigida entonces por el fiscal Luis Moreno-Ocampo ${ }^{5}$, había pedido una condena de treinta años. ¿Por qué entonces la reducción de la pena a menos de la mitad de los solicitado? El argumento esgrimido por el juez Fulford

${ }^{2}$ La Corte Penal Internacional es una institución constituida por dieciocho magistrados elegidos, según lo dispuesto en el art. 36.1 del Estatuto de la CPI, por nueve años no renovables. Son cuatro sus órganos de funcionamiento: Presidencia, 3 Secciones, Fiscalía y Secretaría.

La CPI no funciona en pleno, sino a través de sus tres Secciones o Salas: Sala de Apelaciones (formada por cinco jueces), Sala de Primera Instancia (tres jueces) y Sala de Cuestiones Preliminares (uno o tres jueces).

${ }^{3}$ ICC-01/04-01/06-2842, Case The Prosecutor v. Thomas Lubanga Dyilo (Situation in Democratic Republic of the Congo). Decisión según el art. 74 del Estatuto CPI. El texto de la sentencia puede consultarse en www.icc-cpi.int/iccdocs/doc/doc1379838.pdf.

${ }^{4}$ ICC-01/04-01/06-2901. Decisión según el art. 76 del Estatuto CPI. El texto de la sentencia puede consultarse en www.icc-cpi.int/iccdocs/doc/doc1438370.pdf.

${ }^{5}$ Desde el 14 de junio de 2012 la nueva fiscal de la CPI es la gambiana Fatou Bensouda, que era desde 2004 segunda fiscal de la Corte. 
(presidente de la Sala de Primera Instancia de la CPI) es que se habían tenido en cuenta dos factores a la hora de fijar la pena:

- La buena conducta del acusado y su plena colaboración con la CPI.

- Los múltiples errores cometidos a lo largo de todo el proceso por el entonces fiscal Moreno-Ocampo, así como su fracaso a la hora de presentar algunos datos cruciales del caso.

Importantes son las dos sentencias mencionadas, pero quizá más significativa aún ha sido la sentencia de 7 de agosto de 2012 en la que la CPI establece los principios y el proceso de reparación a las víctimas de los crímenes cometidos por Thomas Lubanga ${ }^{6}$, pues constituye un precedente sin igual en el ámbito de los derechos de las víctimas de graves violaciones de los derechos humanos y del derecho humanitario.

Todas estas sentencias han sido dictadas en el marco de un complejo proceso, caracterizado no sólo por su larga duración (más de seis años), sino por las diversas vicisitudes que surgieron a lo largo del mismo, motivadas principalmente por una conducta errática de la Fiscalía, que sirven para ilustrar la tensión que existe entre la presión por aplicar sanciones a las personas que han cometido graves crímenes internacionales y los derechos de los acusados. Todo lo cual coadyuvará, sin duda, para que la Corte Penal Internacional corrija sus deficiencias y mejore su funcionamiento futuro ${ }^{7}$.

${ }^{6}$ ICC-01/04-01/06-2904. Decisión según el art. 75 del Estatuto CPI. El texto de la sentencia puede consultarse en www.icc-cpi.int/iccdocs/doc/doc1447971.pdf.

${ }^{7} \mathrm{La}$ CPI ha emitido hasta la fecha un total de dieciocho órdenes de arresto en siete situaciones distintas. Actualmente están abiertos los siguientes casos:

- Situación en Uganda. El fiscal contra Joseph Kony, Vincent Otti, Okot Odhiambo y Dominic Ongwen: cuatro órdenes de arresto dictadas contra los líderes del Ejército de Resistencia del Señor. Los cuatro están prófugos y se presume que se encuentran escondidos entre Uganda y la RDC; se les acusa de crímenes de lesa humanidad.

- Situación en la República Democrática del Congo. El fiscal contra Bosco Ntaganda: acusado de crímenes de guerra y de lesa humanidad; está prófugo y se presume está escondido en la RDC. El fiscal contra Germain Katanga y Mathieu Ngudjolo Chui: el juicio comenzó en 2009 con la comparecencia de ambos acusados a los que se acusa de crímenes de lesa humanidad.

- Situación en Darfur, Sudán. El fiscal contra Abmad Muhammad Harun y Ali Mubammad Ali: ambos están prófugos de la CPI y están acusados de crímenes de lesa humanidad y de guerra cometidos en la provincia oriental del Darfur. El fiscal contra Omar Hassan Abmad Al Bashir: el presidente del Sudán está acusado de crímenes de lesa humanidad, crímenes de guerra y genocidio en Darfur; es la única orden de arresto emitida por la CPI en contra de un jefe de Estado en activo. El fiscal contra Abdallah Banda Abakaer Nourain, Saleb Mohammed Jerbo Jamus: Banda y Jerbo comparecieron ante la CPI y las acusaciones en su contra fueron confirmadas. El fiscal contra Abdel Raheem Mubammad Hussein (minis- 


\section{EL COMPLEJO CASO THE PROSECUTOR V. THOMAS LUBANGA DYILO}

\section{Los hechos y los cargos}

Thomas Lubanga Dyilo es un ciudadano congoleño de la etnia Hema nacido en Jiba el 29 de diciembre de 1960; psicólogo de profesión, está casado y tiene siete hijos.

Lubanga es uno de los más temibles señores de la guerra de la República Democrática del Congo. Como comandante militar del Reagrupamiento Congoleño para la Democracia-Movimiento de Liberación Nacional (RDC-ML) fue un actor fundamental de las dos guerras del Congo. La primera librada desde finales de 1996 hasta mediados de 1997 y la segunda que tuvo lugar desde 1998 hasta finales de $2003^{8}$.

Presuntamente, en el año 2002 Thomas Lubanga creó la Unión de Patriotas Congoleños (UPC), un grupo rebelde constituido principalmente por miembros de la etnia Hema — ganaderos- y cuya ala militar es la Fuerza Patriótica para la Liberación del Congo (FPLC), de la que Lubanga es su comandante en jefe.

Este movimiento rebelde se enfrentó durante los años 2002 y 2003 a las milicias de la etnia Lendu —agricultores—, entre ellas a la Armada Popu-

tro de Defensa y ex ministro del Interior del Sudan): se le acusa de crímenes de lesa humanidad y crímenes de guerra.

- Situación en la República Centroafricana. El fiscal contra Jean-Pierre Bemba Gombo: el ex vicepresidente de RDC y actual senador está siendo acusado de crímenes de lesa humanidad y crímenes de guerra cometidos bajo su mando en la incursión congoleña a la RCA.

- Situación en Kenia. El fiscal contra William Samoei Ruto y Joshua Arap Sang: comparecieron voluntariamente los acusados y fueron confirmados los cargos por crímenes de lesa humanidad; no se encuentran en custodia de la CPI. El fiscal contra Francis Kirimi Muthaura y Uburu Muigai Kenyatta: comparecieron voluntariamente ante los jueces y los cargos de crímenes de lesa humanidad fueron confirmados por la Sala e irán a juicio, si bien no se encuentran en custodia de la CPI.

- Situación in Libia. La Corte abrió una investigación en Libia por indicación del Consejo de Seguridad de Naciones Unidas y dictó tres ordenes de arresto en contra de Muammar Mohammed Abu Minyar Gaddafi, Saif Al-Islam Gaddafi y Abdullah Al-Senussi por crímenes de lesa humanidad. Debido a la muerte de Muammar Gaddafi, el caso en su contra fue cerrado. Su hijo, Saif Al-Islam, se encuentra detenido por el bastión rebelde en Zintan y Al Senussi; se debate si el poder judicial libio está en condiciones y capacidad de llevar a juicio al hijo de Gaddafi y a Al-Senussi.

- Situación en Costa de Marfil. El fiscal contra Laurent Gbagbo: Gbagbo, acusado de crímenes de lesa humanidad, fue detenido por autoridades locales y transferido a la Corte.

${ }^{8}$ Esta segunda es conocida como la «Guerra Mundial de África» y en ella se calcula que murieron 3,8 millones de personas, la mayoría de hambre y enfermedad. 
lar Congolesa y a la Fuerza de Resistencia Patriótica. Enfrentamientos que tuvieron lugar en la región de Ituri, al noreste de la República Democrática del Congo, una zona llena de recursos naturales, fundamentalmente madera, oro, diamantes, coltan y petróleo — del que se han encontrado cantidades importantes en el valle de Semliki-. Como consecuencia de la guerra entre ambas etnias por hacerse con el control de la región murieron más de 60.000 personas. Fue precisamente allí donde fueron obligados a batirse los más de 3.000 niños soldados que Lubanga había reclutado para la FPLC. No sólo eso, sino que los niños menores de quince años - casi todos pertenecientes a la etnia Hena de la región de Ituri- eran obligados a luchar, a actuar como guardaespaldas de sus superiores y a realizar tareas domésticas. Las niñas — también se reclutaron niñas soldados-, además de ser obligadas a luchar, eran forzadas a convertirse en esclavas sexuales de los comandantes del FPLC.

Finalizada la guerra, las autoridades congoleñas ordenaron la captura de los rebeldes. Sin embargo, en abril de 2004, y sobre todo tras el asesinato de nueve cascos azules de Naciones Unidas, el gobierno de la República Democrática del Congo (RDC) decidió remitir el asunto a la Corte Penal Internacional según lo dispuesto en los arts. 13.a) y 14 del Estatuto?.

Emitida la orden de arresto contra Thomas Lubanga Dyilo por la Sala de Primera Instancia, éste fue capturado en Kinshasa (RDC) en marzo de 2005, siendo trasladado un año más tarde —el 16 de marzo de 2006 - al Centro de Detención de la CPI en Scheveningen (La Haya) en un avión fletado al efecto por el ejército francés. El 20 de marzo de 2006, Thomas

${ }^{9}$ La competencia de la CPI no es principal, sino subsidiaria de la de los Estados; de tal forma que ésta sólo puede conocer de un asunto porque el mismo le sea remitido por un Estado parte del Estatuto (o bien porque se lo remite el Consejo de Seguridad por tratarse de una situación que esté conociendo en el marco del Capítulo VII de la Carta de la ONU), según lo dispuesto en los arts. 13 y 14 del Estatuto que disponen lo siguiente:

«Art. 13. Ejercicio de la competencia.-La Corte podrá ejercer su competencia respecto de cualquiera de los crímenes a que se refiere el art. 5 de conformidad con las disposiciones del presente Estatuto si: a) Un Estado Parte remite al fiscal, de conformidad con el art. 14, una situación en que parezca haberse cometido uno o varios de esos crímenes».

«Art. 14. Remisión de una situación por un Estado Parte.-1. Todo Estado Parte podrá remitir al fiscal una situación en que parezca haber cometido uno o varios crímenes de la competencia de la Corte y pedir al fiscal que investigue la situación a los fines de determinar si ha de acusar de la comisión de tales crímenes a una o varias personas determinadas.

2. En la medida de lo posible, en la remisión se especificarán las circunstancias pertinentes y se adjuntará la documentación justificativa de que disponga el Estado denunciante».

A este respecto recordemos que, como ya hemos indicado, la República Democrática del Congo se convirtió en Estado Parte del Estatuto el 1 de julio de 2002, tras depositar su instrumento de ratificación el 11 de abril de ese mismo año. 
Lubanga comparece por primera vez ante la Sala de Cuestiones Preliminares de la $\mathrm{CPI}^{10}$.

En agosto de 2006, Thomas Lubanga fue acusado de crímenes de guerra por la Fiscalía. Habida cuenta las múltiples y variadas atrocidades de las que fue responsable Lubanga, la pregunta que inmediatamente se suscita es: ¿de cuáles exactamente? Pues bien, a la vista de los hechos, el fiscal Moreno-Ocampo decidió «limitar» los cargos únicamente a los de «reclutamiento, alistamiento y uso de niños y niñas menores de quince años en un conflicto armado interno durante el periodo de 1 de septiembre de 2002 a 13 de agosto de 2003», tal y como queda tipificado en el art. 8.2.e). vii) del Estatuto de la $\mathrm{CPI}^{11}$. Fuera quedaron, pues, otras denuncias de crímenes de guerra igualmente tipificados en el Estatuto y cometidos por la FPLC bajo mandato de Lubanga, como, por ejemplo, las relativas al crimen de esclavitud sexual [art. 8.2.e).vi)]. Una decisión incomprensible a la luz de las pruebas presentadas, que fue incluso criticada por los propios jueces de la Corte, quienes mostraron su sorpresa al respecto cuando tuvieron ocasión de hacerlo. La única explicación dada por el fiscal a tal reducción de cargos fue la de «agilizar el proceso» —un proceso que, debido a los «errores» del fiscal, duró más de seis años-.

A lo largo de tres semanas, del 9 al 28 de noviembre de 2006, se llevaron a cabo tres audiencias de vista a los efectos de ratificar los cargos, en las que participaron cuatro víctimas que presentaron sus puntos de vista y opiniones. El 29 de enero de 2007, la Sala de Cuestiones Preliminares confirmó los cargos contra Thomas Lubanga en los términos expresados por la Fiscalía (reclutamiento, alistamiento y uso de niños soldados durante el periodo de 1 de septiembre de 2002 a 13 de agosto de 2003), decidiendo llevar el caso a juicio; correspondiendo esta fase ya a la Sala de Primera Instancia.

${ }^{10}$ Todos los pormenores del caso Thomas Lubanga Dyilo pueden consultarse en la web de la CPI: www.icc-cpi.int/Menus/ICC/Situations+and+Cases/Situations/ Situation+ICC+0104.

${ }^{11}$ «Art. 8. Crímenes de guerra.-2. A los efectos del presente Estatuto, se entiende por "crímenes de guerra":

e) Otras violaciones graves de las leyes y los usos aplicables en los conflictos armados que no sean de índole internacional dentro del marco establecido de Derecho internacional, a saber, cualquiera de los actos siguientes:

vii) Reclutar o alistar niños menores de quince años en las fuerzas armadas o grupos, o utilizarlos para participar activamente en hostilidades». 


\section{El complicado proceso contra Lubanga}

Compareciente ante la Corte en marzo de 2006, acusado por el fiscal en agosto de 2006 y confirmados los cargos por la Sala de Cuestiones Preliminares en enero de 2007, el juicio contra Thomas Lubanga no comienza sino dos años más tarde, el 26 de enero de 2009. Y ello debido a diversos incidentes en el proceso que no hicieron sino alargar y complicar aún más un procedimiento de por sí arduo y complejo. «Incidencias» provocadas principalmente por la actitud, la conducta y los errores del fiscal del caso, Luis Moreno-Ocampo, que son, sin duda, una de las notas que más caracteriza este primer asunto de la Corte Penal Internacional.

En esta línea, la primera complicación que se presentó en el proceso fue la relativa a la «confidencialidad» de ciertas pruebas —más de cienque el fiscal se negaba a mostrar a la Defensa de Lubanga. Ésta alegaba que dichas pruebas podían ser relevantes para demostrar la inocencia de su defendido, por lo que solicitó que fueran desclasificadas. El fiscal, no obstante, se negó a entregarlas aduciendo que las había recibido bajo el compromiso de confidencialidad de acuerdo con el art. 54.3.e) del Estatuto, que dispone expresamente que el fiscal podrá «convenir en que no divulgará en ninguna etapa del procedimiento los documentos o la información que obtenga a condición de preservar su carácter confidencial y, únicamente, a los efectos de obtener nuevas pruebas, salvo con el acuerdo de quien haya facilitado la información».

En nuestra opinión, la Fiscalía ha hecho un uso demasiado generoso del art. 54.3.e) prometiendo confidencialidad sin tener en cuenta sus obligaciones de divulgación, así como los correspondientes derechos del acusado. A este respecto debemos advertir que el argumento esgrimido por el fiscal resulta falaz, pues el propio Estatuto también dispone en su art. 67.2 que «el fiscal divulgará a la Defensa, tan pronto como sea posible, las pruebas que obren en su poder o estén bajo su control y que, a su juicio, indiquen o tiendan a indicar la inocencia del acusado, o a atenuar su culpabilidad, o que puedan afectar a la credibilidad de las pruebas de cargo; en caso de duda acerca de la aplicación de este párrafo, la Corte decidirá».

Así pareció entenderlo también la Sala de Primera Instancia de la CPI, que el 13 de julio de 2008 ordenó que la información requerida se hiciera accesible a la Defensa. A pesar de la orden de la Corte, el fiscal no cumplió, por lo que el 2 de julio de 2008 la Sala de Primera Instancia dictaminó el sobreseimiento del caso y ordenó la puesta en libertad de Thomas 
Lubanga por considerar que no se estaban dando las garantías de un debido proceso. Una decisión que causó enorme perturbación, ya que podía significar no sólo echar por la borda años de investigación y poner en peligro la seguridad de aquellos que venían colaborando con la Corte en el caso, sino que podía dañar gravemente la credibilidad de la propia Corte Penal Internacional —no exenta de importantes detractores- Hubo quien incluso llegó a solicitar la dimisión inmediata del fiscal ${ }^{12}$.

El 11 de julio, la Fiscalía apeló esta decisión y pidió la suspensión de la orden de libertad del acusado. Tras negociar con Naciones Unidas acerca de la posible desclasificación de las pruebas - la mayoría de las cuales se había obtenido por conducto de dicha organización-, el fiscal accedió a divulgar las mismas. A la vista de tales hechos, el 12 de octubre de 2008 la Sala de Apelaciones dictó dos resoluciones: en la primera denegó la solicitud del fiscal de dar curso inmediato al juicio oral y en la segunda dejó sin efecto la orden de liberación de Thomas Lubanga, afirmando que la Sala se había equivocado al decir que la liberación del acusado era la consecuencia inevitable de la suspensión del proceso y renvió el asunto nuevamente a la Sala de Primera Instancia. El 18 de noviembre de 2008, esta última anunció su decisión de reanudar el juicio el 26 de enero de 2009, dado que las razones por las que se impuso la suspensión ya no existían, así como que el señor Lubanga no gozaría del derecho a tener libertad provisional durante la celebración del juicio.

El 26 de enero de 2009, la CPI abrió por fin su primer juicio contra Thomas Lubanga. La Fiscalía, la Defensa, la Secretaría y ocho representantes legales de 93 víctimas participaron en las audiencias judiciales. La Fiscalía terminó la presentación de su caso a mediados de julio de 2009. Sin embargo, la presentación de los argumentos por parte de la Defensa, prevista originariamente para el mes de octubre, tuvo que aplazarse debido a una nueva interrupción del proceso.

En este caso, el origen de la suspensión vino motivado porque el 22 de mayo de 2009 se presentó una demanda conjunta de los representantes de las víctimas - de conformidad con lo previsto en la norma 55.2 del Reglamento de la $\mathrm{CPI}^{13}$ — en la que solicitaban la «re-caracterización» de

${ }^{12}$ Cf. J. Rozenberg, Telegraph-UK, 2 de julio de 2008.

${ }_{13}$ El Reglamento de la CPI fue aprobado por los magistrados el 26 de mayo de 2004 (ICC-BD/01-01-04; disponible en www.iccnow.org/documents/RegulationsCourt_Spanish. $p d f)$. Su norma 55 dispone:

«Autoridad de la Sala para modificar la tipificación jurídica de los hechos.-1. En su fallo conforme al art. 74, la Sala podrá modificar la tipificación jurídica de los hechos para que dé 
los hechos y la ampliación de los cargos originales imputados a Thomas Lubanga por el fiscal, a los efectos de incluir «la esclavitud sexual» y los «tratos crueles e inhumanos»-tipificados en los ars. 8.2.e).vi) y 8.2.c).i), respectivamente ${ }^{14}$ - A juicio de los representantes de las víctimas, existían numerosas pruebas de sendos crímenes que se habían presentado a lo largo del juicio, sobre todo por lo que se refiere a actos de violencia sexual contra las niñas soldado. La Sala de Primera Instancia consideró que sí se daban los elementos previstos en la norma 55.2 para la inclusión de una lista adicional de cargos, por lo que el 14 de julio de 2009 procedió a informar favorablemente la solicitud presentada por las víctimas.

Apelada la decisión de la Sala de Primera Instancia por la Defensa, el 8 de diciembre de 2009 la Sala de Apelaciones rechazó dicha decisión, aun cuando reconoció que efectivamente sí había evidencia sustancial sobre actos de violencia sexual realizados por el FPLC; sin embargo, entendía la Sala de Apelaciones que no procedía la recalificación puesto que la norma 55 no puede utilizarse para ir más allá de los hechos imputados en el escrito de acusación de la Fiscalía ${ }^{15}$, el cual se había limitado al reclutamiento, alistamiento y uso de niños soldados.

cuenta tanto de delitos conforme a los arts. 6, 7 u 8 como de una forma de participación del acusado conforme a los arts. 25 y 28 , siempre que no se excedan los hechos y las circunstancias descritos en los cargos y en cualquier modificación de los cargos.

2. Si en cualquier momento durante el juicio la Sala considera que la tipificación jurídica de los hechos puede estar sujeta a cambios, la Sala deberá notificar dicha posibilidad a los participantes y, una vez practicadas las pruebas, en la etapa procedente del procedimiento, dará a los participantes la oportunidad de realizar observaciones verbales o escritas en tal sentido. La Sala puede suspender una audiencia para asegurar que los participantes tengan tiempo y medios adecuados para realizar una preparación eficaz o, de ser necesario, puede ordenar que se celebre una audiencia para considerar todas las cuestiones inherentes al cambio propuesto.

3. A los efectos del num. 2, la Sala deberá en particular asegurarse de que el acusado:

a) Disponga del tiempo y los medios adecuados para preparar eficazmente su defensa según se establece en el apartado b) del párrafo 1 del art. 67.

b) Tenga oportunidad, de ser necesario, de interrogar o hacer interrogar nuevamente a un testigo anterior, convocar a nuevos testigos o presentar otras pruebas admisibles conforme al Estatuto según se establece en el apartado e) del párrafo 1 del art. 67».

${ }^{14} \mathrm{El}$ art. 8.2.e).vi) tipifica como crimen de guerra: «Cometer actos de violación, esclavitud sexual, prostitución forzada, embarazo forzado (definido en el apartado $f$ ) del párrafo 2 del art. 7), esterilización forzada o cualquier otra forma de violencia sexual que constituya también una violación grave del art. 3 común a los cuatro Convenios de Ginebra». Por su parte, el art. 8.2.c).i) tipifica: «Los atentados contra la vida y la integridad corporal, especialmente el homicidio en todas sus formas, las mutilaciones, los tratos crueles y la tortura».

15 A este respecto debemos advertir que en marzo de 2012, la CPI ha añadido estos dos crímenes (esclavitud sexual y tratos crueles e inhumanos) a la orden de detención ya dictada 
El 7 de enero de 2010 se reanuda el juicio con los testimonios de dos expertos y tres víctimas, y la posterior presentación de los argumentos por parte de la Defensa. Sin embargo, el proceso vuelve a suspenderse nuevamente el 8 julio de ese año al considerar la Sala de Primera Instancia que no era posible asegurar el desarrollo de un juicio justo en tanto la Fiscalía no cumpliera las órdenes dictadas por la Sala. En este sentido, el problema venía originado por la negativa del fiscal a revelar la identidad de ciertos intermediarios - en concreto el intermediario 143-.

A este respecto, hay que tener presente que el caso de la acusación contra Thomas Lubanga se fundamenta principalmente en los testimonios de víctimas, esto es, de personas que afirman haber sido reclutadas como niños soldado por Lubanga. Estos testimonios fueron obtenidos por la Fiscalía a través de la figura de los «intermediarios», esto es, operadores locales externos a la Corte que operaban en el terreno con la responsabilidad de localizar a potenciales víctimas, si bien no sólo localizaban a los testigos, sino que los habían preparado para facilitar un testimonio que resultara útil a la acusación. En este contexto, resultó que el primer testigo de la acusación se retractó de su testimonio en un momento posterior, afirmando que había sido manipulado por estos intermediarios; a éste se unieron algunos testigos más que señalaron que habían sido inducidos a mentir e, incluso, que les habían ofrecido dinero a cambio de su testimonio. La revelación de tan graves acusaciones llevó a la Defensa a denunciar la existencia de falsos testimonios, aportando documentación relevante al respecto. Los abogados de Lubanga — Catherine Mabile y Biju Duval— arguyeron que el expediente del fiscal estaba «gangrenado» por un intento de manipulación de testigos del cual el fiscal tenía conocimiento. Por ello, alegaron que era necesario conocer la identidad de tres de esos intermediarios (los nús. 143, 316 y 321); solicitud que fue aceptada por la Sala de Primera Instancia, la cual instó al fiscal —12 de mayo de 2010 - a que revelara dicha identidad. Sin embargo, éste se negó argumentando que no podía poner en riesgo la seguridad del intermediario 143.

Ante la negativa a acatar la petición de la Sala, ésta dictaminó nuevamente el sobreseimiento del caso - 8 de julio de 2010 - y la puesta en libertad del acusado — 15 de julio de $2010^{16}$ —. En opinión de la Sala, esta negativa del fiscal a cumplir su decisión constituía un auténtico abuso de

contra uno de los adjuntos de Lubanga, Bosco Ntaganda, que actualmente lidera el grupo armado M23 en la provincia de Kivu septentrional, en el este de la RDC.

${ }^{16}$ Los magistrados argumentaron que un acusado no puede permanecer en custodia preventiva sobre una base especulativa. 
procedimiento (párr. 31), y tal conducta de rebeldía implicaba que no se podía seguir garantizando el debido proceso (párr. 27). La decisión de sobreseimiento y puesta en libertad fue apelada por el fiscal, quien llegó a argumentar que no existía una relación de jerarquía entre la Sala y la Fiscalía, motivo por el cual no tenía que cumplir sus dictados.

Apeladas las decisiones de la Sala de Primera Instancia, la Sala de Apelaciones sostuvo — 8 de octubre de 2010 — que el fiscal había violado el Estatuto al no cumplir las órdenes de la Sala, pues, según el art. 64 del Estatuto, corresponde a ésta velar porque se aseguren las condiciones de un juicio justo en el que se respeten los derechos del acusado, y que, en materia de protección de participantes en el proceso, es la Corte quien tiene la última palabra y no el fiscal. No obstante, la Sala de Apelaciones revocó tanto la decisión de puesta en libertad de Lubanga como el sobreseimiento, al considerar que todavía podían darse las condiciones de un juicio justo donde la Sala de Primera Instancia tuviera el control del procedimiento. Asimismo, instó a ésta a imponer sanciones al fiscal, así como a abstenerse de adoptar la drástica medida del sobreseimiento (párr. 60).

Reanudado el proceso, éste fue nuevamente suspendido a principios de 2011 durante seis semanas debido a varias cuestiones de la Defensa que dificultaban el caso relacionadas, en concreto, con la revelación de testigos y víctimas. El 23 de febrero de 2011, la Sala de Primera Instancia rechazó otra nueva petición de la Defensa de suspender el procedimiento y el juicio se reanudó el 21 de marzo, terminando la fase de presentación de pruebas el 20 de mayo.

Los días 25 y 26 de agosto de 2011 tuvieron lugar las conclusiones finales del juicio.

El 14 de marzo de 2012, en una audiencia pública, la Sala de Primera Instancia entregó su veredicto, una sentencia de casi 600 páginas adoptada por unanimidad, en la cual Thomas Lubanga Dyilo fue hallado culpable a título de coautor del crimen de guerra tipificado en el art. 8, literal 2.e).vii), del Estatuto de la CPI, dado que había quedado probado que Lubanga reclutó y alistó a niños menores de quince años de edad con el objeto de utilizarlos activamente en conflictos armados desarrollados entre el 1 de septiembre de 2002 y el 13 de agosto de 2003. La Sala de Primera Instancia de la CPI determinó que el crimen fue cometido en el contexto de un conflicto armado interno - y no internacional— que tuvo lugar en el distrito de Ituri.

En el veredicto, los tres jueces no desaprovecharon la ocasión para criticar la labor desarrollada por el fiscal a lo largo de todo el proceso. En 
varios comentarios críticos, la Sala señala que la Fiscalía actuó con negligencia, ocasionándole considerables pérdidas de tiempo y dinero. Los aspectos más relevantes que fueron criticados son: los cargos presentados, el uso de la figura de los intermediarios y la calidad de la investigación. Por contra, si la actuación del fiscal del caso, Luis Moreno-Ocampo, dejó mucho que desear, no hay duda alguna de la equidad demostrada por los jueces a lo largo de todo el proceso en pro de las garantías del debido proceso y de los derechos del acusado.

Los aspectos más destacables de la sentencia de 14 de marzo de 2012, sobre todo de cara a futuros casos pendientes de la Corte, son: la definición y participación de las víctimas; la presentación y valoración de las pruebas; el carácter del conflicto armado; la tipificación del crimen de guerra del reclutamiento, alistamiento y utilización de niños soldados, y la coautoría como modo de responsabilidad, incluyendo el elemento subjetivo ${ }^{17}$.

\section{LA SENTENCIA DE 7 DE AGOSTO DE 2012 SOBRE LOS PRINCIPIOS Y EL PROCESO DE REPARACIÓN A LAS VÍCTIMAS DE LOS CRÍMENES DE THOMAS LUBANGA}

\section{Del derecho a la reparación}

Ahora bien, si significativa para las víctimas es la condena de Thomas Lubanga en la medida que constituye una indudable victoria para ellas, no debemos olvidar que se trata de una victoria simbólica, pues, indudablemente, lo realmente importante para las víctimas es conseguir la adecuada reparación del daño que se les ha causado.

A este respecto debemos señalar que es un principio de Derecho internacional que toda violación de una obligación comporta el deber de reparar de forma adecuada el daño causado, tal y como sentenció la Corte Permanente de Justicia Internacional en el asunto de la fábrica de Chorzow $(1928)^{18}$, y que recoge el art. 31 del Proyecto de artículos de

${ }_{17}$ Un análisis detallado de todos estos aspectos de la decisión de 14 de marzo de 2012 puede consultrase en K. AmBos, «El primer fallo de la Corte Penal Internacional (Prosecutor v. Lubanga): un análisis integral de las cuestiones jurídicas», InDret, 3 (2012), disponible en www.indret.com/pdf/903a.pdf.

${ }_{18}$ PCIJ, Serie A, núm. 17, p. 47, disponible en www.icj-cij.org/pcij/index.php?p1=9Ep2 $=1 \& p 3=0 \& C O=A 17$. 
la CDI sobre responsabilidad del Estado por hechos internacionalmente ilícitos de $2001^{19}$.

Si la reparación del daño es fundamental siempre que haya una violación de una obligación internacional, más importante aún lo es cuando estamos ante graves violaciones de derechos humanos, como es el presente caso en el que se han cometido crímenes de guerra.

En este sentido, el Derecho internacional de los derechos humanos consagra el derecho de los particulares a la reparación por los daños sufridos en caso de violación de los tratados que recogen tales derechos, así como el derecho a un recurso efectivo en caso de violación de los mismos. Un reconocimiento que se produce tanto a nivel universal como regional.

Así, el derecho a la reparación está reconocido en las siguientes disposiciones: art. 9.5 del Pacto Internacional de Derechos Civiles y Políticos de 1966; art. 14 de la Convención contra la Tortura de 1984; art. 39 de la Convención sobre los Derechos del Niño de 1989; art. 6 de la Convención sobre la eliminación de todas las formas de discriminación racial de 1965; art. 3 del Convenio de La Haya sobre leyes y costumbres de guerra de 1907; art. 91 del Protocolo I de las Convenciones de Ginebra sobre protección a las víctimas de conflictos armados de 1977; art. 41 de la Convención Europea para la Protección de los Derechos Humanos y las Libertades Fundamentales de 1950; art. 63.1 de la Convención Americana de Derechos Humanos de 1969, o el art. 21.1 de la Carta Africana de los Derechos Humanos y de los Pueblos.

Por lo que se refiere al derecho a un recurso efectivo en caso de violación de un derecho fundamental, el mismo está reconocido en el art. 8 de la Declaración Universal de los Derechos Humanos; en el art. 2.3 de Pacto Internacional de Derechos Civiles y Políticos; en el art. 13 de la Convención Europea para la Protección de los Derechos Humanos y las Libertades Fundamentales de 1950; en el art. 25 de la Convención Americana de Derechos Humanos de 1969, y en el art. 7 de la Carta Africana de los Derechos Humanos y de los Pueblos.

En idéntico sentido encontramos los Principios y Directrices básicos de Naciones Unidas sobre el derecho de las víctimas de violaciones manifiestas de las normas internacionales de derechos humanos y de violaciones graves del Derecho internacional humanitario a interponer recursos y

19 «Art. 31. Reparación.-1. El Estado responsable está obligado a reparar íntegramente el perjuicio causado por el hecho internacionalmente ilícito». 
a obtener reparaciones de 16 de diciembre de $2005^{20}$, en los que la reparación adopta una fisonomía que va más allá de la tradicional dimensión económica, incluyendo aspectos relacionados con la verdad, la justicia y, en último término, con la memoria, como ingredientes esenciales de todo proceso integral de reparaciones.

En línea con estas disposiciones, la jurisprudencia de los tribunales regionales de derechos humanos, así como de los diversos Comités de Naciones Unidas, es contundente en el reconocimiento del derecho a la reparación del que disfrutan las víctimas de violaciones de derechos humanos ${ }^{21}$.

Incluso el propio Tribunal de Justicia de la Unión Europea ha reconocido a favor de los particulares un derecho a obtener reparación en caso de violación del Derecho comunitario por uno de sus Estados miembros [asuntos Francovich (1991) y Brasserie de Pechêur (1993)].

En este sentido, si histórica es la sentencia de 14 de marzo de 2012 por ser la primera decisión de la CPI reconociendo la culpabilidad de un individuo, tanto o más lo es la sentencia de 7 de agosto de 2012 por ser la primera decisión de la CPI sobre los principios y el proceso para las reparaciones a las víctimas; en este caso, a las víctimas de los crímenes imputados a Thomas Lubanga.

En consonancia con lo anterior, la sentencia de 7 de agosto recalca la finalidad que se persigue con la reparación, cual es la de aliviar el sufrimiento causado por los graves crímenes cometidos, proporcionar justicia a las víctimas atenuando las consecuencias de la violación, impedir futuras violaciones y contribuir a la efectiva reintegración de las víctimas (párr. 179). Llegando a reconocer que el derecho a la reparación es «un derecho humano básico bien establecido» (párr. 185).

Ahora bien, creemos necesario reseñar que esta sentencia no es una orden de reparación, pues no está decidiendo realmente la reparación concreta a cada una de las víctimas, tal y como sí sucede en los casos que se sustancian ante el Tribunal Europeo de Derechos Humanos (TEDH) o ante la Corte Interamericana de Derechos Humanos (CIDH), sino que se limita a establecer las bases, los principios que deberán regir las repa-

${ }^{20}$ Principios aprobados por la Resolución de la Asamblea General de Naciones Unidas A/RES/60/147, de 21 de marzo de 2006.

${ }^{21}$ Un análisis de la jurisprudencia más relevante de los referidos órganos de protección con relación al derecho a la reparación en casos de violaciones graves de derechos humanos puede consultarse en E. Lambert AbDelgawad y K. Martin-Chenut (dirs.), Réparer les violations graves et massives des droits de l'homme: La Cour Interaméricaine, pionnière et modèle?, París, Société de Législation Comparée, 2010. 
raciones que se realizarán en un momento posterior, así como el procedimiento mediante el cual se harán efectivas las mismas. Todo lo cual ya no será competencia de esta Sala de Primera Instancia de la CPI, sino que la misma delega tan importante labor en el Fondo Fiduciario en Beneficio de las Víctimas —órgano no judicial de la Corte Penal Internacional—, cuyo trabajo a este respecto será supervisado por una nueva Sala.

Es decir, estamos aún en un punto y seguido de este largo proceso contra Thomas Lubanga. A las víctimas les queda todavía camino por recorrer; un camino que se presume dilatado, sobre todo si tenemos en cuenta que tanto la Defensa como los representantes de las víctimas han apelado la sentencia de 7 agosto de 2012 sobre reparaciones, solicitando todos ellos que se anule dicha decisión.

\section{Los principios de reparación establecidos en la sentencia de 7 de agosto de 2012}

A diferencia de la sentencia de 14 de marzo que se caracteriza, entre otros, por su excesiva extensión — casi 600 páginas—, la decisión de 7 agosto de 2012 cuenta con 94 páginas, de las cuales sólo las 30 últimas son las que realmente establecen los principios y el proceso de reparación, mientras que las primeras 64 son puramente introductorias y expositivas de las diversas alegaciones presentadas por las partes y otros organismos con relación a las reparaciones, sin que se observe que hayan tenido la menor trascendencia en la fijación posterior de los principios.

Tras fundamentar su competencia para poder dictar esta decisión — de la cual no hay duda alguna a tenor de lo dispuesto por el art. 75 del Estatuto $^{22}$ relativo a la reparación a las víctimas-, la Sala de Primera Instancia

${ }^{22} \mathrm{El}$ art. 75 del Estatuto de la CPI dispone lo siguiente:

«1. La Corte establecerá principios aplicables a la reparación, incluidas la restitución, la indemnización y la rehabilitación, que ha de otorgarse a las víctimas o a sus causahabientes. Sobre esta base, la Corte, previa solicitud o de oficio en circunstancias excepcionales, podrá determinar en su decisión el alcance y la magnitud de los daños, pérdidas o perjuicios causados a las víctimas o a sus causahabientes, indicando los principios en que se funda.

2. La Corte podrá dictar directamente una decisión contra el condenado en la que indique la reparación adecuada que ha de otorgarse a las víctimas, incluidas la restitución, la indemnización y la rehabilitación. Cuando proceda, la Corte podrá ordenar que la indemnización otorgada a título de reparación se pague por conducto del Fondo Fiduciario previsto en el art. 79.

3. La Corte, antes de tomar una decisión con arreglo a esta artículo, podrá solicitar y tendrá en cuenta las observaciones formuladas por el condenado, las víctimas, otras personas o Estados que tengan un interés, o las que se formulen en su nombre. 
aborda la interesante cuestión del derecho aplicable para fijar la reparación (párr. 185-186) regulada por el art. 21.1 del Estatuto.

A este respecto, el citado precepto remite, en primer lugar, al propio Estatuto de la Corte, así como a las Reglas de Procedimiento y Prueba. Sin embargo, no es en estos textos donde la Sala encuentra el derecho a aplicar, sino que, aunque no lo diga expresamente, hace uso de la segunda opción que le facilita el apartado $b$ ) del art. $21^{23}$ y recurre a estos efectos a los tratados, los principios y las normas del Derecho internacional. Resultando así que los textos que fundamentalmente le sirven de guía para establecer los principios de reparación son los siguientes:

- Principios y Directrices básicos de Naciones Unidas sobre el derecho de las víctimas de violaciones manifiestas de las normas internacionales de derechos humanos y de violaciones graves del Derecho internacional humanitario a interponer recursos y a obtener reparaciones, 2005.

- Declaración de principios básicos de justicia para las víctimas de delitos y abuso de poder, 1985.

- Directrices sobre justicia en caso de víctimas infantiles, ECOSOC-2005.

- Declaración de Nairobi sobre el derecho de las mujeres y las niñas a interponer recurso y a obtener reparaciones, 2008.

- Principios de Ciudad del Cabo y buenas prácticas sobre el reclutamiento de niños en conflictos armados en África, 1997.

4. Al ejercer sus atribuciones de conformidad con el presente artículo, la Corte, una vez que una persona sea declarada culpable de un crimen de su competencia, podrá determinar si, a fin de dar efecto a una decisión que dicte de conformidad con este artículo, es necesario solicitar medidas de conformidad con el párrafo 1 del art. 93.

5. Los Estados Parte darán efecto a la decisión dictada con arreglo a este artículo como si las disposiciones del art. 109 se aplicaran al presente artículo.

6. Nada de lo dispuesto en el presente artículo podrá interpretarse en perjuicio de los derechos de las víctimas con arreglo al Derecho interno o el Derecho internacional».

23 «Art. 21. Derecho aplicable.-1. La Corte aplicará:

a) En primer lugar, el presente Estatuto, los elementos de los crímenes y sus reglas de procedimiento y prueba.

b) En segundo lugar, cuando proceda, los tratados aplicables, los principios y normas del Derecho internacional, incluidos los principios establecidos del Derecho internacional de los conflictos armados.

c) En su defecto, los principios generales del Derecho que derive la Corte del Derecho interno de los sistemas jurídicos del mundo, incluido, cuando proceda, el Derecho interno de los Estados que normalmente ejercerían jurisdicción sobre el crimen, siempre que esos principios no sean incompatibles con el presente Estatuto ni con el Derecho internacional ni las normas y estándares internacionales reconocidas». 
- Principios de París sobre los niños asociados a fuerzas armadas o grupos armados, 2007.

Pero la Sala no se limita a acogerse a las normas y principios del Derecho internacional de los derechos humanos, como le permite el art. 21.1.b), sino que, además, explícitamente manifiesta que le servirá de orientación la jurisprudencia desarrollada en la materia por los tribunales regionales de derechos humanos; una fuente que no está recogida de manera expresa como posible derecho aplicable en el art. 21 del Estatuto.

En todo caso, debemos advertir que, a pesar de la profusión en la enumeración de fuentes, un examen en detalle de la decisión adoptada sobre los principios de reparación nos lleva a la conclusión de que dos han sido sus principales fuentes de «inspiración»: los Principios y Directrices de Naciones Unidas de 2005 y la jurisprudencia de la Corte Interamericana de Derechos Humanos.

Sobre la base del Derecho aplicable reseñado, los principios para las reparaciones que se recogen en la decisión de 7 de agosto de 2012 pueden sintetizarse en los siguientes ${ }^{24}$ :

1. El derecho a la reparación es un derecho bumano bien establecido en distintos tratados internacionales de derechos humanos.

2. Las víctimas deben ser tratadas de forma justa y equitativa, pudiendo ser consideradas como tales tanto las que han participado en el proceso como las que no lo han hecho. En este sentido, se deben tener en cuenta las necesidades de todas las víctimas y, en particular, las de los niños, las de las personas de avanzada edad, las de los discapacitados y las de las víctimas de violencia sexual o sexista.

Las víctimas deben ser tratadas con respeto y dignidad.

Las medidas de reparación se tomarán sin ningún tipo de discriminación, tal y como la edad, la etnia o el sexo.

3. Las reparaciones pueden ser acordadas tanto a las víctimas directas como a las indirectas, incluidas las familias y las personas que han intervenido para ayudar a las víctimas directas, así como las entidades jurídicas, tales como ONGs u hospitales. Por lo que se refiere a las víctimas indirectas, deben demostrar la existencia de una relación personal estrecha entre ellas y la víctima directa, como por ejemplo la que existe entre un niño soldado y sus padres.

${ }^{24}$ Véase a este respecto: www.vrwg.org/accueil/accueil/post/37-affaire-lubanga---questionsreponses-concernant-la-decision-majeure-de-la-cpi-sur-les-reparations-pour-les-victimes. 
4. Las reparaciones deben ser accesibles para todas las víctimas siguiendo una aproximación sensible al género. Las víctimas, sus familias y sus comunidades deberán poder participar en el proceso de reparación y recibir una reparación adecuada.

5. Las medidas de reparación deberán tener en cuenta la violencia sexual que hayan podido sufrir las víctimas, así como las consecuencias complejas de estos crímenes. Se debe permitir a las mujeres y las niñas tener acceso a la justicia.

6. Las reparaciones deberán tener en cuenta la edad de las víctimas, así como la necesidad de rebabilitar y reinsertar en sus comunidades a los antiguos niños soldados. A estos efectos, se deberá tener como guía la Convención sobre los Derechos del Niño y asegurar y respetar los derechos del niño.

7. Las reparaciones pueden ser individuales o colectivas. Las reparaciones individuales deberán adoptarse de tal forma que no se generen tensiones en el seno de las comunidades. Si se adoptan reparaciones colectivas, éstas deberán abarcar los perjuicios que las víctimas hubieran sufrido, tanto de forma individual como colectiva, y se deberá atender a las víctimas que aún no han sido identificadas.

8. Las reparaciones podrán adoptar la forma de restitución, indemnización, rehabilitación u otras formas más simbólicas, como las campañas de sensibilización:

- Restitución: restablecer a las víctimas a su situación anterior en la que se encontraban antes del crimen; regresar con sus familias, a su educación, o a su trabajo; devolver los bienes y propiedades que les hubieren sido quitados.

- Indemnización: deberá englobar todos los daños físicos, como, por ejemplo, la imposibilidad de quedarse embarazada; los daños morales y no materiales resultantes del sufrimiento físico, mental y emocional; los daños materiales, abarcando la pérdida de bienes; las oportunidades perdidas, incluidas las relativas al empleo, la educación o el estatus social, y los derechos legales y los costes desembolsados, tales como los de los expertos jurídicos, los servicios médicos o la ayuda social recibida.

- Rehabilitación: incluyendo servicios médicos, escolarización u ofertas de trabajo.

- Reparaciones simbólicas: tales como conmemoraciones y homenajes; publicación de la sentencia; campañas para mejorar la posición de las víctimas; certificados reconociendo el perjuicio sufrido; actividades de información, o programas de educación. 
9. Las víctimas deberán recibir reparaciones apropiadas, rápidas y adecuadas. Las reparaciones deberán ser proporcionales a los perjuicios, al sufrimiento, a las pérdidas y al daño resultante de los crímenes.

Se debe buscar la reconciliación de las víctimas, sus familias y todas las comunidades afectadas por los hechos, y reflejar, en la medida de lo posible, las prácticas culturales y las costumbres locales.

10. El daño, pérdida o perjuicio que constituyan la base de una demanda de reparación deberá haber sido resultado de los crímenes de reclutamiento, alistamiento y utilización de niños soldados imputables a Thomas Lubanga.

Sin embargo, las medidas de reparación no deben limitarse al «daño directo» o a los «efectos inmediatos» de estos crímenes, sino que deberán basarse en el principio de «causa próxima» (but for test).

11. Los hechos que sean pertinentes para una orden de reparación deberán probarse sobre la base de la «preponderancia de probabilidades».

12. Los Estados deberán cooperar plenamente en la ejecución de las órdenes de reparación.

13. Estos principios y todos los procesos de reparación que se lleven a cabo por la CPI deberán ser públicos y deberán comprender actividades de sensibilización con las autoridades nacionales, las comunidades locales y las poblaciones afectadas.

\section{El proceso a seguir}

Sin duda, una de las peculiaridades más reseñables de esta sentencia sobre reparaciones es el hecho de que, como ya hemos advertido, no va a ser la propia Sala de Primera Instancia que ha conocido el caso desde sus inicios quien va a conocer de las solicitudes de reparación, ni va a decidir las medidas concretas de reparación para cada una de las víctimas de los crímenes de Thomas Lubanga. En su lugar, la Sala ha optado por delegar esta compleja y trascendental labor en el Fondo Fiduciario en Beneficio de las Víctimas.

El Fondo Fiduciario es una de las innovaciones más importantes introducidas por el Estatuto de Roma respecto a las víctimas. Fue creado para ayudar a cumplir con la función de la Corte de reparar a las víctimas de los crímenes bajo su competencia, de acuerdo a lo dispuesto por el art. 79(1) del Estatuto, la norma 98 de las Reglas de Procedimiento y Prueba, y la 
Resolución 6 de la Asamblea de los Estados Partes del 9 de septiembre de 2002. El Fondo Fiduciario es un órgano independiente de la Corte cuyos fondos provienen de cuatro fuentes primarias: órdenes de reparación dictadas por la Corte en contra de personas condenadas; fondos recaudados por medio de multas y decomisos; contribuciones voluntarias hechas por Estados, individuos y organizaciones, y otros recursos asignados por la Asamblea de los Estados Partes.

Las funciones desempeñadas por el Fondo Fiduciario son fundamentalmente tres:

- ayudar a implementar las órdenes de reparación que le hayan sido transferidas por la CPI contra personas condenadas bajo la regla 98 (2)-(4);

- utilizar las contribuciones que recibe a modo de contribuciones voluntarias para financiar proyectos en beneficio de las víctimas y de sus familias;

- desarrollar e implementar políticas que apoyen la recaudación de fondos para el Fondo Fiduciario.

El Fondo Fiduciario está regido por un Consejo de Dirección en el que están representados los cinco grupos regionales de Naciones Unidas. Los miembros del Consejo son: su majestad la reina Rania de Jordania (Asia); el arzobispo Desmond Tutu, ex presidente de la Comisión de la Verdad y Reconciliación de Sudáfrica (África); su excelencia el señor presidente Oscar Arias Sánchez, ex presidente de Costa Rica (América Latina); la señora Simone Veil, ex ministra de Salud de Francia y ex presidenta del Parlamento Europeo (Europa occidental y otros Estados), y su excelencia el señor Tadeusz Mazowiecki, ex primer ministro de Polonia (Europa oriental).

A los efectos de abordar el mandato de las reparaciones a las víctimas de Lubanga, la Sala recomienda al Fondo Fiduciario, en su decisión de 7 de agosto, que cree un equipo multidisciplinar de expertos para ayudarle en las tareas de:

- evaluar el daño sufrido;

- evaluar el efecto que han tenido los crímenes de los niños soldados sobre sus familias y su comunidad;

- identificar la forma más apropiada de reparación;

- establecer a qué individuos, órganos, grupos o comunidades se les debe otorgar reparación, y

- acceder a los fondos necesarios para este propósito. 
El equipo estará compuesto por representantes del gobierno de la República Democrática del Congo, representantes internacionales y especialistas en cuestiones de infancia y género.

Asimismo, la Sala ha establecido un plan de cinco pasos para implementar las reparaciones, a tenor del cual el Fondo Fiduciario, en colaboración con la Secretaría de la CPI, la Oficina Pública para las Víctimas y el equipo de expertos, deberán:

1. Identificar las localidades que deberán involucrarse en el proceso de reparación, particularmente los lugares donde fueron cometidos los crímenes.

2. Realizar consultas en las localidades.

3. Valorar el daño sufrido por las víctimas.

4. Realizar debates públicos en cada localidad para explicar los principios y el proceso de reparaciones.

5. Recoger las propuestas para las reparaciones colectivas que tengan que desarrollarse en cada localidad.

Todos estos pasos del plan deberán ser supervisados por una nueva Sala de la Corte Penal Internacional.

Por otra parte, dado que Thomas Lubanga se ha declarado indigente y que no posee ningún bien que pueda ser utilizado para las reparaciones, éstas serán financiadas a través del Fondo Fiduciario para las Víctimas, razón por la cual la Sala ha pedido la colaboración de todos los Estados, sean o no partes del Estatuto de la CPI.

Tal y como advertíamos en páginas precedentes, esta decisión de 7 de agosto de 2012 ha sido apelada tanto por la Defensa como por los representantes de las víctimas, quienes han solicitado la anulación de la misma ${ }^{25}$.

Por lo que se refiere a la Defensa, cuatro son los aspectos fundamentales refutados en su apelación: 1) la Sala no puede desentenderse del caso en beneficio de otra Sala;2) la Sala no puede delegar en un órgano no judicial el poder para establecer sobre cuestiones que necesitan poderes exclusivos, como la designación de expertos, la identificación de las víctimas o la determinación del daño sufrido por éstas; 3 ) las medidas de reparación acordadas son demasiado vagas; y 4) la reparación sólo puede acordarse a las personas que han sufrido un perjuicio personal, actual y cierto; no

\footnotetext{
${ }_{25}$ Todas las apelaciones del caso Lubanga pueden consultarse en el siguiente enlace: www.icc-cpi.int/menus/icc/situations\%20and\%20cases/situations/situation\%20icc\%200104/ related\%20cases/icc\%200104\%200106/court\%20records/chambers/appeals\%20chamber.
} 
cabe reparación, ni a las víctimas que no han participado en el proceso, ni a aquellas que han sufrido un daño indirecto.

Por su parte, las víctimas también objetan cuatro puntos de la decisión sobre reparaciones, por los que consideran que la Sala de Primera Instancia ha cometido un error de derecho: 1) al desentenderse del asunto en la fase de reparaciones en beneficio de una nueva Sala; 2) al delegar sus responsabilidades en materia de reparación en dos entidades no judiciales, como son el Fondo para las Víctimas y la Secretaría; 3) al rechazar las demandas de reparación individuales sin analizarlas; y 4) al exonerar al acusado de cualquier obligación con relación a la reparación, aunque fuera de forma alternativa.

\section{Algunas reflexiones acerca de la sentencia sobre reparaciones}

No hay duda, como venimos señalando, de la importancia de esta decisión de 7 de agosto de 2012 sobre reparaciones, que viene a reforzar el importante papel de las víctimas en el Derecho penal internacional.

Una sentencia que, a nuestro juicio, cuenta con importantes aspectos positivos, otros no tanto e incluso algunos conflictivos. A ellos queremos referirnos brevemente.

La primera afirmación de la decisión de 7 de agosto que nos parece cuando menos reseñable es la contenida en el párrafo 181, en el que la Sala afirma que: «Although in this decision the Trial Chamber has established certain principles relating to reparations and the approach to be taken to their implementation, these are limited to the circumstances of the present case».

Ciertamente cada caso es diferente, tiene sus particularidades y habrá que ajustar las reparaciones a las circunstancias del mismo. Esto ha sido, es y será siempre así. Pero es la primera vez que un tribunal internacional, estableciendo además, no una reparación concreta, sino unos principios generales de reparación, afirma que éstos no van a generar «jurisprudencia». Insólito y ciertamente perturbador. Sobre todo si tenemos en cuenta que la Sala ha establecido estos principios de reparación tomando como referencia la previa jurisprudencia de otros tribunales de derechos humanos, los cuales, evidentemente, decidieron la reparación caso por caso ajustándose a las circunstancias de cada uno de ellos, pero inspirándose en su jurisprudencia anterior.

A nuestro juicio, tal enunciación nos parece absolutamente desafortunada —e incluso contraria al propio Estatuto de la CPI-. 
Mención especial merece la cuestión relativa a los beneficiarios de la reparación, por diversos aspectos relativos a la misma que pasamos a exponer.

Ya hemos advertido que beneficiarios son tanto las víctimas directas como las indirectas, incluyendo a la familia y a aquellas personas que hubieran sufrido un daño cuando ayudaban o intervenían en nombre de las víctimas, así como a las personas jurídicas. En este punto, la Sala se acoge plenamente al concepto amplio de víctima recogido tanto en el principio 8 de los Principios y Directrices de 2005, como en la jurisprudencia de los tribunales regionales de derechos humanos - TEDH y $\mathrm{CIDH}$-, e incluso en los Comités de Naciones Unidas ${ }^{26}$. Asimismo, resulta coherente con otras decisiones anteriores de la propia Corte Penal Internacional.

El único problema a este respecto que intuimos, y que deberá afrontar en su momento el grupo de expertos, es el de determinar el alcance exacto de la noción de «familia», pues hasta la fecha estábamos acostumbrados a la jurisprudencia europea y americana que se acoge al concepto tradicional de familia, entendiendo por tal a los hijos, los padres y los cónyuges, y aquí deberán tenerse en cuenta las variaciones culturales propias del continente africano.

Igualmente positivo nos parece que la Sala de Primera Instancia no haya limitado la posibilidad de participar en el proceso de reparación, y, por tanto, ser beneficiario de la misma, únicamente a las víctimas que habían participado en el proceso contra Thomas Lubanga, cuyo total ascendía a 129 víctimas. Sino que, por el contrario, se ha ampliado la caracterización de víctimas a todas las posibles víctimas anónimas de los crímenes de reclutamiento, alistamiento y utilización de niños soldados cometidos del 1 de septiembre de 2002 al 13 de agosto de 2003, que ahora tienen la posibilidad de personarse en este proceso de reparaciones.

${ }^{26}$ Baste citar a este respecto, a título ejemplificativo, el caso Almeida de Quinteros (1982), en el que el Comité de Derechos Humanos consideró que la madre de la desaparecida fue también víctima de la tortura y otros tratos crueles, inhumanos y degradantes sufridos directamente por la hija, o el caso Suárez de Guerrero c. Colombia (1982), en el que el esposo fue considerado víctima por el Comité. Por su parte, el TEDH también ha reconocido el derecho de los parientes a la reparación. Desde el caso Kurt c. Turquía (1998), el Tribunal ha sostenido que los parientes de una persona desaparecida pueden ellos mismos ser considerados víctimas de tortura y otros tratos crueles, inhumanos o degradantes. En idéntico sentido se ha pronunciado la CIDH en los casos Velasques c. Hondura, Niños de la Calle c. Guatemala o Juan Humberto Sánchez c. Honduras, entre otros. Y también la Comisión Africana de Derechos Humanos y de los Pueblos en el caso Asociación Africana de Malawi et al. c. Mauritania (2000), donde se recomendó pagar una compensación económica a las viudas y beneficiarios de las víctimas de desapariciones forzadas. 
Ahora bien, esta ampliación de beneficiarios a todas las posibles víctimas puede conllevar dos consecuencias negativas: una, retardar el proceso de reparación, sobre todo por lo que se refiere a la identificación de las mismas; otra, habida cuenta el escaso montante económico del que dispone el Fondo Fiduciario, un elevado número de víctimas puede supone una considerable reducción de la cuantía de las reparaciones de carácter económico. Esto, evidentemente, favorecerá sin duda que se opte por las reparaciones colectivas en detrimento de las reparaciones individuales que, con toda probabilidad, no llegarán a ser consideradas. Esto puede traducirse en que la reparación no sea todo lo completa que los principios de Derecho exigen.

Por otra parte, en este mismo contexto nos parece muy positivo, a la par que controvertido, el principio según el cual deberán ser tenidos en cuenta, a efectos de reparación, «los actos de violencia sexual que hayan sufrido las víctimas». Con ello, la Sala de Primera Instancia de la CPI deja abierta la puerta a la potencial inclusión como víctimas de aquellas que lo son por ofensas sexuales, tales como la «esclavitud sexual»; esto es, el cargo no imputado por el fiscal Moreno-Ocampo a Thomas Lubanga y que las propias víctimas quisieron añadir en un momento posterior, pero que fue rechazado por la Sala de Apelaciones. Este principio nos parece positivo porque es una forma de compensar el error cometido en su momento por el fiscal, pero al mismo tiempo puede resultar conflictivo, porque puede ser considerado como un exceso de la Corte.

En esta misma línea crítica, por problemática, situaríamos el «test de causalidad» aplicado por la Sala de Primera Instancia. Como hemos señalado, ésta ha establecido en su decisión de 7 de agosto que la reparación no debe limitarse al daño directo o al efecto inmediato de los crímenes cometidos por Thomas Lubanga, sino que deberá basarse en el principio de la causa próxima, esto es, en el «but for test» (párr. 246). El llamado «but for test $\gg$ es el criterio en virtud del cual las consecuencias de un acto se imputan al autor de éste si tales consecuencias no hubieran tenido lugar sin tal acto; una «but for cause» sería la causa sin la cual no hubiese ocurrido el daño, es decir, la condición indispensable para que éste ocurriera, aun cuando no fuese la causa exclusiva de ese daño o lesión, ni siquiera la primera.

Evidentemente se trata de un test de causalidad mucho más amplio que el del daño directo, que, por ende, favorece la reparación a las víctimas; así, por ejemplo, en el marco de dicha causalidad es evidente que quedarían cubiertos los daños derivados de la esclavitud sexual, en la medida en que los mismos no habrían tenido lugar si no se hubiera reclutado y utilizado a las niñas soldado. Ahora bien, una aplicación excesiva de este test 
puede llegar a generar una ilimitada responsabilidad que puede extender la causalidad de una forma demasiado amplia.

En tercer lugar, por lo que se refiere a las modalidades de reparación, la Sala de Primera Instancia ha optado por la aplicación de la más variada gama de medidas de reparación posible. En este punto es evidente que ha seguido la estela tanto de los Principios y Directrices de 2005 como de la jurisprudencia de la Corte Interamericana de Derechos Humanos. Esta última es, sin lugar a dudas, la más prolija y detallada en cuanto a medidas de reparación a las víctimas de violaciones graves de derechos humanos. Mucho más progresista que su homólogo, el Tribunal Europeo de Derechos Humanos, que es más conservador en la materia, limitándose a establecer meras compensaciones económicas como modalidad de reparación ${ }^{27}$. Resulta así que todas las modalidades de reparación fijadas en la decisión de 7 de agosto de 2012 tienen su reflejo en alguno o algunos casos de la CIDH, como los conocidos: Velásques, Garrido y Baigorri, Castillo Páez, Instituto Juvenil de Reeducación, La Masacre de Dos Erres, Barrios Altos, El Amparo, Cantoral, Trujillo Oroza, Huilca Tecse, Goiburu, etc.

A nuestro juicio, optar por una lista tan prolija de medidas puede no ser tan positivo como pareciera. Sobre todo porque se plantea un problema que la Sala parece desconocer.

Es evidente que la Sala ha optado no por averiguar cuáles son las modalidades de reparación más adecuadas al caso, sino por recoger todas las posibles; esto es, ha sido inclusiva. Y lo ha hecho sin darse cuenta que las medidas que toma como referente, esto es, las adoptadas por la CIDH o, en algunos casos, por el TEDH, son medidas destinadas a ser aplicadas por los Estados que han cometido la violación de los derechos humanos. Y en el presente caso, el autor de la grave violación de los derechos humanos no es un Estado, sino un individuo. La pregunta que surge entonces es: ¿quién va aplicar estas medidas? El problema no es en relación con la indemnización, pues, como sabemos, la misma la asume el Fondo Fiduciario en Beneficio de las Víctimas, sino respecto de todas las demás medidas. ¿A quién le corresponde aplicarlas?

${ }^{27}$ Debemos, no obstante, advertir que desde finales de 2006 se observa un tímido cambio en la jurisprudencia del TEDH en este sentido. Observamos así que el TEDH empieza a decidir otras formas de reparación. Así, por ejemplo, en el asunto Okkkali c. Turquía (2006) establece, como reparación, la obligación de realizar una investigación efectiva y oficial que conduzca a la identificación y castigo a los culpables. En el mismo sentido, el asunto Aksakal c. Turquía (2007) o el asunto Velikova y otros 7 c. Bulgaria (2007), en el que ordenó la reapertura de una investigación por malos tratos. 
No hay duda que la Sala de Primera Instancia ha optado por aplicar la técnica del llamado «cross-fertilization», esto es, la práctica de algunos tribunales internacionales consistente en retomar criterios de otros tribunales internacionales para aplicarlos a sus propios casos. Ésta es una práctica muy utilizada por la CIDH que retoma criterios de los tribunales penales cuando quiere fundamentar una conducta que constituye una grave violación de los derechos humanos. También ha sido utilizada por la Corte Internacional de Justicia, como ha ocurrido en su reciente sentencia de 19 de junio de 2012 en el asunto Abmadou Sadio Diallo, en la que acude a la práctica de otros tribunales y órganos de control en materia de derechos humanos a los efectos de determinar la correcta indemnización de la víctima en sus diferentes aspectos ${ }^{28}$ : reparación del daño inmaterial, daños personales, pérdida de remuneración por la detención ilegal y expulsión.

Ninguna objeción a dicha práctica cuando estamos en contextos similares, esto es, tribunales juzgando Estados. Ahora bien, aquí la utilización se produce en un contexto diferente, pues la CPI retoma criterios para Estados con la finalidad de aplicarlos con relación a individuos; es decir, está recogiendo medidas de reparación pensadas originariamente para ser aplicadas por Estados infractores. Esto, en ocasiones, es factible (vuelta a la familia, indemnización), pero en otras resulta una auténtica utopía. Así, por ejemplo, pensemos en las medidas propuestas por la Sala de programas de rehabilitación para las víctimas, campañas de sensibilización, ofertas de trabajo... ¿A quién van dirigidas estas medidas? ¿Quién tiene que cumplirlas?

Este problema es consecuencia directa de la expresa exclusión en el Estatuto de la posible corresponsabilidad del Estado por los crímenes de sus nacionales; si tal se hubiera recogido no tendríamos este problema. Resulta así que la implementación de la mayoría de las modalidades de reparación establecidas por la Sala de Primera Instancia necesitan indefectiblemente de la cooperación de los Estados, bien de la República Demo-

${ }^{28}$ Dice expresamente la Corte Internacional de Justicia en su párrafo 13: «La Cour se penchera maintenant sur la question de l'indemnisation due au titre des violations des droits de l'homme subies par M. Diallo, dont elle a constaté l'existence dans son arrêt du 30 novembre 2010 [...] La Cour tient compte de la pratique d'autres juridictions et commissions internationales (telles que le Tribunal international du droit de la mer, la Cour européenne des droits de l'bomme (CEDH), la Cour interaméricaine des droits de l'bomme (CIADH), le Tribunal des réclamations Etats-Unis/Iran, la Commission des réclamations entre l'Erythrée et l'Ethiopie et la Commission d'indemnisation des Nations Unies), qui ont appliqué les principes généraux régissant l'indemnisation lorsqu'elles ont été appelées à fixer le montant d'une indemnité, notamment à raison du préjudice découlant d'une détention ou d'une expulsion illicites» (www.icj-cij.org/docket/files/103/17045.pdf). 
crática del Congo, bien de otros. Por ello, creemos que la Sala debería haber sido más selectiva en sus medidas.

Por último, una reflexión final por lo que se refiere al proceso a seguir para la puesta en práctica de las reparaciones.

Si bien es cierto, como alega la Sala de Primera Instancia, que la decisión de reenviar la ejecución de las reparaciones a otros órganos puede entrar en el marco del poder discrecional del que disfruta la CPI, también lo es que, dada la importancia de la materia, nos parece una decisión, cuando menos, cuestionable y que, además, no cuenta con ningún precedente en ninguna instancia internacional. En efecto, no existe precedente en la materia de un órgano judicial que esté conociendo un caso y que: primero, renvíe la importante cuestión de la reparación a otro órgano distinto, y menos aún a uno que es de carácter político como lo es el Fondo Fiduciario; y segundo, que para supervisar el proceso se desentienda y decida que se cree una nueva Sala que desconoce por completo todo el caso.

Curiosamente, toda la decisión de 7 de agosto de 2012 está basada en la jurisprudencia de otros tribunales internacionales de derechos humanos en la materia, salvo en este punto concreto, donde, a nuestro parecer, la innovación de la Corte Penal Internacional resulta absolutamente declinable.

En todo caso, al margen de las eventuales críticas que pudieran hacerse a la decisión de 7 de agosto, debemos quedarnos con lo positivo, cual es que las víctimas de los crímenes de Thomas Lubanga Dyilo van a conseguir la debida reparación.

Es evidente que la reparación no es una panacea que, cual bálsamo de Fierabrás, vaya a solucionar ipso facto los problemas de las víctimas; el mal cometido no desaparece, es sólo mitigado. Por no hablar que hay ciertas secuelas que resultan irreparables y que, en ocasiones, las heridas son de tal naturaleza que a lo máximo que se puede aspirar es a que las víctimas aprendan a vivir con su dolor. Pero ante todo debemos recordar que al conseguir una reparación, tal y como afirmara el juez Cançado Trinda$\mathrm{de}^{29}$, «el silencio, la indiferencia y el olvido no han logrado sobreponerse a las atrocidades, y que el mal perpetrado no ha prevalecido sobre la perenne búsqueda de la justicia».

${ }^{29}$ Voto razonado del juez A. A. Cançado Trindade en el caso Niños de la Calle (Villagrán Morales y otros) c. Guatemala, Sentencia de 26 de mayo de 2001, Reparaciones, Serie C, núm. 77, párr. 43. 